\title{
Ecology of the coastal heath forest flora - a case study from Terengganu, Malaysia
}

\begin{abstract}
This study was conducted to determine the floral diversity and biomass in a coastal heath forest at Rantau Abang, Terengganu, Malaysia. The plot included contiguously arranged 100 subplots $(10 \mathrm{~m} \times 10 \mathrm{~m})$. Results showed that 959 trees of 63 species belonging to 52 genera and 30 families are distributed in this coastal forest. Myrtaceae is the largest family (163 trees) followed by Annonaceae (160 trees) and Lecythidaceae (100 trees). Euphorbiaceae is the most diverse family containing 6 genera and 6 species. Syzygium claviflorum var. claviflorum (15.5\%) was the dominant species followed by Polyalthia hypogaea $(12.7 \%)$ and Barringtonia macrostachya (10.4\%). Dipterocarpaceae has a small stocking as compared to the non-dipterocarp families in this forest. This family comprised about $9 \%$ of tree density and $6 \%$ of tree species diversity. The dominant species from Dipterocarpaceae is Shorea materialis. The total biomass in the forest lies around 249 ton/ha. The largest contribution to the biomass comes from Dipterocarpaceae with 86 ton/ha (34.5\%) followed by Myrtaceae 75.3 ton/ha $(30.2 \%)$. The biomass contribution of Shorea materialis is 78.8 ton/ha, followed by Syzygium claviflorum 67.8 ton/ha. The biomass of Champereia griffithii is 0.006 ton/ha.
\end{abstract}

Keyword: Coastal heath forest; Floral diversity; Ecology; Biomass 